\title{
The Deterioration of Paper on Ageing
}

$\mathrm{T}$

HE problem of the permanence of paper is one which is of particular interest to scientific workers. The rapid increase in the volume of scientific publications is causing grave concern to all learned societies, and these are exerting their financial resources to the utmost in order to keep in pace with it. It is unfortunate that in many cases the printing quality and the appearance and feel of a paper have been the principal factors which have influenced those choosing it, but as these qualities do not necessarily go hand in hand with permanence, future generations of members may find that the efforts of their predecessors have been wasted.

The problem is one of recent origin, for it is only since 1860,1870 , and 1880 respectively that esparto grass, mechanical wood pulp, and chemical wood pulp have been used in paper-making. Prior to 1860 , rags (that is, cotton, flax, and hemp) were the usual raw materials, and although excessive loading, bleaching, or alum may shorten the life of rag papers, they are generally recognised as being the most permanent. This fact was, indeed, recognised so far back as 1898 in a Report to the Royal Society of Arts, in which it was stated that esparto and straw papers are more permanent than mechanical pulp papers, but less permanent than chemical pulp papers. It was therefore specified that permanent book papers should contain less than ten per cent of loading and not less than seventy per cent of rag.

Subsequent work in the United States and in Germany has modified the inferences drawn from this Report, since it has been shown that the method of manufacture of the paper and the conditions of storage are equal in importance to the nature of the fibre in determining how long the paper will last. Bulletin No. 2795 (1912) of the American Newspaper Publishers' Association, for example, points out that excessive dryness (resulting from the artificial heating of libraries) and excessive dampness may alter the normal moisture content of the paper, and so stimulate its deterioration. Cases are on record in which a badly-made rag paper had undergone rapid deterioration, whilst at the other extreme hand-made mechanical wood-pulp has been stored under proper conditions for a hundred years and still shows no sign of ageing.

A Committee of the League of Nations also pronounced in favour of unbleached rag papers in 1928 , and quite recently the investigation has been taken up by the Bureau of Standards in the United States (Miscellaneous Publication No. 128, Research Papers Nos. 349 and 352). Not only have opinions been expressed as to storage conditions, but in addition, what appears at first sight to be a revolutionary recommendation is made, namely, that the paper may be prepared from any fibres except those of unbleached or mechanical wood-pulps. The great difficulty in arriving at trustworthy results is due, of course, to the impossibility of carrying out tests under the conditions of practice. Not only would this take too long, but it must also be remembered that the earliest commercial papers made from wood or esparto are not more than seventy-five years old, and, moreover, that the extensive improvements in manufacturing methods in the meantime have resulted in a corresponding improvement in the paper of to-day. The Bureau of Standards and others have therefore had to resort to accelerated ageing tests, the actual technique of which varies from one investigator to another and may involve heating for seventy-two hours at $40^{\circ}$ to $100^{\circ} \mathrm{C}$., with or without exposure to sunlight or ultra-violet rays.

B. L. Wehmhoff, who as technical director of the Government Printing Office at Washington must be regarded as an authority on such matters, has recently devoted some attention to them in a paper before the Technical Section of the Pulp and Paper Industry (Proceedings, 94, 57; 1932). The paper is of value not so much as an account of original work, but because the author has collected the personal opinions of a number of paper experts all over the world on the value of accelerated ageing tests.

The opinions differ widely, but there seems to be general agreement that a temperature of $100^{\circ} \mathrm{C}$. corresponds with rather drastic treatment, and, moreover, that the type of deterioration produced by heat and light is not necessarily the same as that which occurs on storage. Opinions also differ as to the value of chemical tests as a means of determining the permanence of paper. This applies particularly to the $\alpha$-cellulose value, for all agree that the copper number, rosin content, and acidity (or $p \mathrm{H}$ value) should be as low as possible. The effects of traces of impurities also require investigation; for example, there is reason to believe that ferrous iron accelerates the deteriorating influence of rosin.

It is not surprising that specifications for the same type of paper proposed by different bodies are by no means identical. A Report on the subject to H.M. Stationery Office is a cautious and balanced statement of the available facts, and few responsible for the purchase of paper will disagree with the opinions expressed. The Report states that there is no evidence that papers made from esparto or chemical wood deteriorate if stored under proper conditions. At the same time, new, clean, white or unbleached rags are preferable for the best papers, and whenever it is a question of choosing between esparto and chemical wood, the former should be rejected. J. G.

\section{Early Man in Algeria}

I $N$ the course of a recent note on dental mutilation (see Nature, Aug. 20, p. 268) reference was made to its occurrence in fossil human remains from Afaloubou-Rhummel. A communication presented to the first International Congress of Prehistoric and Protohistoric Sciences by MM. Marcellin Boule and Henri Vallois, on "The Fossil Men of Afalou-bou-Rhummel (Algeria)", was welcomed as an authoritative statement on "a new type of fossil man" from North Africa. Prehistoric human skeletal remains have been discovered in North Africa on several occasions, but unfortunately most of them-from the shell-heaps of Tunisia and near Constantine as well from certain Algerian caves-cannot be dated with certainty. The type of Afalou agrees with the type already discovered in Algeria, but the deposits in which previous discoveries have been made are usually regarded as of neolithic age.

The human remains studied in the communication by MM. Boule and Vallois belong to at least fifty individuals; and although they were scattered, nine skeletons have been reconstructed. The cave in which they were found is known by the name of Afalou-bou-Rhummel, and is situated on the Algerian littoral in the commune of Oued Marsa. The cave was excavated in 1928 and 1929 by M. Arambourg with the financial assistance of the Institut de Paléontologie humaine. Both stratigraphical and archæo-

No. 3278, VoL. 130] 